\title{
n-Butylidenephthalide induced apoptosis in the A549 human lung adenocarcinoma cell line by coupled down-regulation of AP-2 $\alpha$ and telomerase activity
}

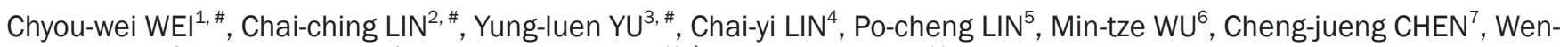
liang CHANG $^{8}$, Shinn-zong LIN $^{9}$, Yi-lin Sophia CHEN ${ }^{10, *}$, Horng-jyh HARN ${ }^{11, *}$

${ }^{1}$ Institute of Biomedical Nutrition, College of Medicines and Nursings, Hungkuang University, Taichung, Taiwan, China; ${ }^{2}$ Graduate Institute of Biotechnology, National Ilan University Ilan, Taiwan, China; ${ }^{3}$ Graduate Institute of Cancer Biology and Center for Molecular Medicine, China Medical University and Hospital, Taichung, Taiwan, China; Department of Biotechnology, Asia University, Taichung, Taiwan, China; ${ }^{4}$ Graduate Institute of Biotechnology, National Ilan University, Ilan, Taiwan, China; ${ }^{5}$ Graduate Institute of Biotechnology, National Dong Hwa University, Hualien, Taiwan, China; ${ }^{6}$ Biotechnology Division, Taiwan Agricultural Research Institute Council of Agriculture, Taichung, Taiwan, China; 'Division of Traumatology, Department of Surgery; Tri-Service General Hospital, Taipei, Taiwan, China; ${ }^{8}$ School of Pharmacy, National Defense Medical Center, Taipei, Taiwan, China; ${ }^{9}$ Center for Neuropsychiatry, China Medical University and Hospital, Taichung, Taiwan, China; ${ }^{10}$ Graduate Institute of Biotechnology, National Ilan University Ilan, Taiwan, China; ${ }^{11}$ Department of Pathology, China Medical University and Hospital, Taichung, Taiwan, China

Aim: To investigate the role of hTERT gene expression and AP-2 $\alpha$ in $n$-butylidenephthalide ( $n$-BP)-induced apoptosis in A549 lung cancer cells.

Methods: Viability of A549 cells was measured by MTT assay. Protein expression was determined by Western blot. Telomerase activity was measured using the modified telomere repeat amplification protocol (TRAP) assay. Xenograft mice were used as a model system to study the cytotoxic effect of $n$-BP in vivo. The morphology of tumor was examined by immunohistochemical staining.

Results: The growth of A549 lung cancer cells treated with $n$-BP was significantly inhibited. Telomerase activity and hTERT mRNA expression were determined by telomeric repeat amplification protocol and reverse transcription-polymerase chain reaction, respectively. $n$-BP inhibited telomerase activity and hTERT mRNA expression in A549 cells while overexpression of hTERT could abolish BPinduced growth inhibition in the A549 cells. We also showed that hTERT promoter activity in the presence of $n$-BP was mediated via AP-2 $\alpha$. We saw an inhibition of tumor growth when nude mice carrying A549 subcutaneous xenograft tumors were treated with $n$-BP. Immunohistochemistry of this tumor tissue also showed a decrease in the expression of hTERT.

Conclusion: The antiproliferative effects of $n$-BP on A549 cells in vitro and in vivo suggest a novel clinical application of this compound in the treatment of lung cancers.

Keywords: human telomerase reverse transcriptase; $n$-butylidenephthalide; AP-2 xenograft; immunohistochemistry

Acta Pharmacologica Sinica (2009) 30: 1297-1306; doi: 10.1038/aps.2009.124; published online 24 August 2009

\section{Introduction}

Telomerase is an RNA-dependent DNA polymerase that synthesizes telomeres after cell division and maintains chromosomal stability, leading to cellular immortalization ${ }^{[1,2]}$. This ribonucleoprotein enzyme consists of a templatecontaining RNA component and a human telomerase

\footnotetext{
\# These authors contributed equally to the work.

* To whom correspondence should be addressed.

E-mail a221865880@yahoo.com.tw (Yi-lin Sophia CHEN) and d15977@ mail.cmuh.org.tw (Horng-jyh HARN)

Received 2009-05-31 Accepted 2009-07-14
}

reverse transcriptase (hTERT) in humans ${ }^{[3-6]}$. High levels of telomerase activity have been detected in germinal cells, immortalized cell lines and $85 \%-90 \%$ of human cancer cells, while most normal somatic cells do not display telomerase activity $^{[7-13]}$. Telomerase activity was seen in most lung cancers and not detected in normal lung tissues ${ }^{[14-17]}$. The presence of telomerase activity in tumors of non-small cell lung cancer patients correlates with a high cell proliferation rate and an advanced pathologic stage ${ }^{[18]}$, making it one of the most important prognostic factors in lung cancer patients and an attractive target in the development of novel therapeutic 
strategies for the treatment of lung cancers.

The expression of hTERT is tightly regulated by various cellular factors such as c-Myc which induces the expression of hTERT and SP1 (stimulating protein-1) which suppresses it $^{[19,20]}$. Two E-boxes and an activating enhancer-binding protein-2 (AP-2) site in a 320-bp region of the hTERT promoter have been shown to be essential for the transcriptional activity of the hTERT gene in RD rhabdomyosarcoma cells ${ }^{[21]}$. AP-2 is an eukaryotic transcription factor required for normal development and morphogenesis during vertebrate embryogenesis. The AP-2 family consists of five different isoforms (AP-2 $\alpha, \mathrm{AP}-2 \beta, \mathrm{AP}-2 \gamma, \mathrm{AP}-2 \delta, \mathrm{AP}-2 \varepsilon$ ) with different biologic functions that are encoded by separate genes. AP-2 expression is tissue- and cell-specific. AP- $2 \alpha$ and $\mathrm{AP}-2 \gamma$ are known to regulate the expression of many cancer-related genes such as HER-2 ${ }^{[22]}, p 21^{[23]}, \mathrm{c}-k i t^{[24]}, b c l-2^{[25]}$, vascular endothelial growth factor ${ }^{[26]}, M U C 18^{[27]}$ and $p 53^{[28]}$. AP-2a has been speculated to act as a tumor suppressor gene. Human cancers of lung, breast, ovary, colon, skin and brain exhibit reduced or no AP-2a expression. Moreover, while expression of dominant negative mutant AP-2a resulted in increased invasiveness and tumorigenicity, overexpression of AP-2a inhibited the growth of cancer cells by promoting apoptosis $^{[26,29-33]}$.

Angelica sinensis (Oliv) Diels (AS), also referred to as dong quai or danggui, is a traditional Chinese medicine used to treat menopausal symptoms. It has been used clinically in the United States to treat gynecological symptoms ${ }^{[34]}$. We previously reported that the chloroform extract of AS (AS-C) and $n$-butylidenephthalide (BP), derived from AS-C, both caused growth arrest and apoptosis of malignant brain tumors and hepatocellular carcinoma (HCC) cells in vitro and in vivo, resulting in tumor inhibition ${ }^{[35-38]}$. We also demonstrated that $n$-BP caused DNA damage followed by cell cycle arrest at the $\mathrm{G}_{0} / \mathrm{G}_{1}$ phase. n-BP-induced apoptosis could not be blocked with either a caspase 8 inhibitor or a $\mathrm{Ca}^{2+}$ blocker leading us to speculate that $n$-BP induced apoptosis could occur via multiple pathways ${ }^{[38]}$.

In the present study, we investigated the role of hTERT gene expression in $n$-BP-induced apoptosis in A549 lung cancer cells. We showed that $n$-BP caused an AP-2a mediated inhibition of telomerase activity and the inhibition was independent of c-Myc or SP1 activation. hTERT promoterdriven luciferase expression was largely attenuated in $n$-BP treated A549 cells suggesting that this regulation was at the transcriptional level. hTERT overexpressing A549 cells that were treated with $n$-BP showed decreased apoptosis and enhanced colony formation efficiency when compared to untransfected cells. These results distinguish the mechanism of action of $n$-BP from that of other pure compounds making it a novel model for understanding the downstream effectors for $n$-BP-induced apoptosis in A549 cells.

\section{Materials and methods}

\section{Cell line and culture}

A549 cells (a human lung carcinoma cell line) were maintained in Dulbecco's modified Eagle's medium supplemented with $10 \%$ heat-inactivated fetal bovine serum (FBS), 100 units $/ \mathrm{mL}$ penicillin and $100 \mu \mathrm{g} / \mathrm{mL}$ streptomycin (Invitrogen, Carlsbad, $\mathrm{CA})$. The cells were incubated at $37^{\circ} \mathrm{C}$ in a humidified atmosphere containing $5 \%$ carbon dioxide. The growth media was changed every 2-3 days per week and subcultured when $80 \%$ confluent.

\section{Chemicals and reagents}

Dulbecco's modified Eagle's medium, fetal bovine serum (FBS), penicillin, streptomycin, trypsin/EDTA, and a NuPAGE Bis-Tris Electrophoresis System (precast polyacrylamide minigel) were purchased from Invitrogen (Carlsbad, CA). An RNA isolation kit was purchased from QIAGEN (Valencia, CA). Dimethyl sulfoxide (DMSO), 3-(4,5-dimethyl thizol-2-yl)2,5-diphenyl tetrazolium bromide (MTT), the PKC inhibitor GF109203X, gambogic acid, beta-actin monoclonal antibody, and horseradish peroxidase-conjugated secondary antibodies were purchased from Sigma Chemical (St Louis, MO). The ERK1/2 kinase inhibitor PD98059 was purchased from R\&D Systems (Minneapolis, MN). The PI3K/AKT inhibitor LY294002 were purchased from Calbiochem (San Diego, CA). Phosphor-GSK-3 $\beta$ (1:1000) rabbit polyclonal antibodies were purchased from Upstate Biotechnology (Lake Placid, NY). Telomerase, hTR, c-Myc, Sp1, AP-2phosphor-AKT (1:1000), phosphor-ERK1/2 (1:2000) and ERK1/2 (1:1000) monoclonal antibodies were purchased from Cell Signaling Technology, Inc (Danvers, MA). Mycoplasma removal reagent was from Dainippon Pharmaceutical Co (Osaka, Japan). The annexin V-FLOUS Staining Kit was from Roche Molecular Biochemicals (Mannheim, Germany). Polyvinylidene difluoride membranes, a bovine serum albumin protein assay kit, and Western blot chemiluminescence reagent were purchased from Amersham Biosciences (Arlington Heights, IL).

\section{Cell growth assay}

Viability of control and treated cells were evaluated using the MTT (Sigma-Aldrich Company, Milan, Italy) assay in triplicate. Briefly, A549 cells $\left(5 \times 10^{3}\right)$ were incubated in 96-well microtiter plate containing $100 \mu \mathrm{L}$ of the growth medium. Cells were permitted to adhere for 16-18 h, and then treated with agents dissolved in medium. After different concentrations $(25,50$, and $100 \mu \mathrm{g} / \mathrm{mL})$ of $n$-BP-containing medium was replaced by fresh medium. The MTT assay was performed after $24 \mathrm{~h}, 48 \mathrm{~h}$, and $72 \mathrm{~h}$. Then cells in each well were incubated at $37^{\circ} \mathrm{C}$ in $50 \mu \mathrm{g}$ of MTT $(5 \mathrm{mg} / \mathrm{mL})$ for $2 \mathrm{~h}$. After the medium and MTT were removed $100 \mu \mathrm{L}$ of DMSO were added to each well. Absorbance at $570 \mathrm{~nm}$ of the mixture was detected using a microplate ELISA reader. The absorbance of untreated cells was considered as $100 \%$. The results were determined by three independent experiments.

\section{Isolation of RNA and RT-PCR}

Total cellular RNA was extracted from cells using the TRIzol ${ }^{\circledR}$ Reagent (Invitrogen, Carlsbad, CA) according to the manufacture's protocol. Then, two $\mu \mathrm{g}$ of total RNA was reverse 
transcribed at $65^{\circ} \mathrm{C}$ for $5 \mathrm{~min}$, after at $37^{\circ} \mathrm{C}$ for $60 \mathrm{~min}$ in the presence of omniscript reverse transcriptase (QIAGEN) according to manufacturer's protocol. One $\mu \mathrm{g}$ of cDNA was amplified in the presence of $20 \mu \mathrm{mol}$ of the following primers: hTERT (F), 5'-CGGAAGAGTGTCTGGAGCAA-3'; hTERT (R), 5'-GGATGAAG-CGGAGTCTGGA-3'; hTR (F), 5' -CTAACCCTAACTGAGAAGGGCGTAG-3'; hTR (R), 5'-GAAGGCGGCAGGCCGAGGCTTTTCC-3'; AP-2a (F), 5'-ACCAGCAACGGGACGGCACGG C-3'; AP-2a (R), 5'-TGGCGGAGACAGCATTGCTGTTG-3' ; GAPDH (F), 5'-TGAAGGTCGGAGTCAACGGATTTGGT-3'; GAPDH (R), 5' -CAT-GTGGGCCATGAGGTCCACCAC-3' with Taq DNA polymerase (Takara Shuzo Co, Shiga, Japan). The thermal cycling profile was composed of an initial denaturation step at $95{ }^{\circ} \mathrm{C}$ for $10 \mathrm{~min}$, 30 cycles of $30 \mathrm{~s}$ of denaturation at $95^{\circ} \mathrm{C}, 30 \mathrm{~s}$ of annealing at $60{ }^{\circ} \mathrm{C}$, and $1 \mathrm{~min}$ of extension at $72{ }^{\circ} \mathrm{C}$, with a final $10 \mathrm{~min}$ extension step at $72{ }^{\circ} \mathrm{C}$. The intensity of bands was analyzed by GS-800 calibrated imaging densitometer (Quantity One 4.0.3 software; Bio-Rad, Hercules, CA), and levels of GAPDH were used as control.

\section{Western blot analysis}

A549 cells were seeded in a $10 \mathrm{~cm}$ dish and later treated with $n$-BP at different doses $(0,25,50$, and $100 \mu \mathrm{g} / \mathrm{mL} ; 0 \mu \mathrm{g} / \mathrm{mL}$ as a vehicle control). Cell pellets were resuspended in lysis buffer [10 nmol/L Tris-HCl (pH 7.5), 1 mmol/L EGTA, 0.5\% 3-[3(cholamidopropyl) dimethylammonio]-1-propanesulfonate, $10 \%(v / v)$ glycerol, $5 \mathrm{mmol} / \mathrm{L}$ beta-2-mercaptoethanol and 0.1 $\mathrm{mmol} / \mathrm{L}$ phenyl-methylsulfonyl fluoride] and incubated on ice for $30 \mathrm{~min}$. After centrifugation at $16000 \times \mathrm{g}$ for $10 \mathrm{~min}$ at 4 ${ }^{\circ} \mathrm{C}$, total cell lysates were collected. The protein concentration of the cell lysates was measured with a Bio-Rad protein assay (Bio-Rad Laboratories, USA) following the manufacturer's instructions. Aliquots $(20 \mu \mathrm{g})$ of the cell lysates were separated by $10 \%-12 \%$ sodium dodecyl sulfate-polyacrylamide gel electrophoresis (SDS-PAGE; Bio-Rad, Hercules, CA, USA) and transferred to polyvinylidenedifluoride (PVDF) membranes (Millipore, USA). The membranes were blocked with 5\% skim milk overnight and probed with an appropriate dilution of primary antibodies for $1 \mathrm{~h}$ at room temperature. The immobilized primary antigen-antibody complex was detected with the respective horseradish peroxidase-conjugated anti-mouse, anti-rabbit IgG secondary antibodies (1/5000 dilution; Cell Signaling Technology, Beverly, MA, USA) for $1 \mathrm{~h}$ at $25^{\circ} \mathrm{C}$, then visualized with an enhanced chemiluminescence (ECL) plus chemiluminescence system (Millipore, USA). The degree of protein expression was calculated as the expression index. The expression indexes were calculated as [(sample intensity/ sample beta-actin intensity)/(vehicle control intensity/vehicle control $\beta$-actin intensity)].

\section{Telomerase activity assay}

Telomerase activity was measured using the modified telomere repeat amplification protocol (TRAP) assay (Roche Diagnostics). Briefly, A549 cells were exposed to either different concentrations of $n$-BP for a given period of $48 \mathrm{~h}$. At the end of the specified incubation time, cells were harvested by centrifugation at $5000 \times g$ for $3 \mathrm{~min}$ at $4{ }^{\circ} \mathrm{C}$. Cell pellets were lysed with $200 \mu \mathrm{L}$ of lysis buffer, incubated on ice for $30 \mathrm{~min}$ and centrifuged for $20 \mathrm{~min}$ at $4^{\circ} \mathrm{C}(16,000 \times g)$. The concentration of protein in the supernatant extracts was measured using a BioRad protein assay (Bio-Rad Laboratories, USA) following the manufacturer's instructions. Typically, $400 \mathrm{ng}$ total protein of the supernatant and $25 \mu \mathrm{L}$ of reaction mixture containing Tris-buffer, telomerase substrate. Positive control was $400 \mathrm{ng}$ total protein of cell lysate extracted from telomeraseexpressing human 293 kidney cells and it was used as positive control. The biotin-labeled P1-TS primer, P2 primer, deoxynucleotide triphosphates (dNTPs) and Taq polymerase were transferred into an assay tube. Sterile water was then added to bring the final volume to $50 \mu \mathrm{L}$. After $20 \mathrm{~min}$ incubation at $25^{\circ} \mathrm{C}$, the reaction mixture was heated at $94{ }^{\circ} \mathrm{C}$ for $5 \mathrm{~min}$ and then subjected to 25 cycles of PCR including denaturation at $94{ }^{\circ} \mathrm{C}$ for $30 \mathrm{~s}$, annealing at $50{ }^{\circ} \mathrm{C}$ for $30 \mathrm{~s}$, and extension at 72 ${ }^{\circ} \mathrm{C}$ for $90 \mathrm{~s}$. The amplification product $(5 \mu \mathrm{L})$ from the PCR reaction was mixed with $20 \mu \mathrm{L}$ of denaturation reagent and incubated at room temperature for $10 \mathrm{~min}$. An aliquot of 225 $\mu \mathrm{L}$ of hybridization buffer was then added to each well. After thorough mixing, $100 \mu \mathrm{L}$ of the mixture from each well was transferred into the precoated microtiter plate (MTP) modules and incubated at $37^{\circ} \mathrm{C}$ for $2 \mathrm{~h}$ with shaking (300 r/min). Antidigoxigenin- peroxidase working solution $(100 \mu \mathrm{L})$ was then added and incubated at room temperature for another 30 min. Then the solution was removed completely from each well and the precipitate was rinsed five times with $250 \mu \mathrm{L}$ of washing buffer for a minimum of $1 \mathrm{~min}$. After removal of the washing buffer, $100 \mu \mathrm{L}$ of POD substrate 3,3',5,5'-tetramethyl benzidine (TMB) substrate solution was added to each well and the mixture was incubated at room temperature for 15 min with gentle shaking for color development. Finally, 100 $\mu \mathrm{L}$ of quenching reagent was added to each well to stop color development and the amount of TRAP products was determined by measuring the absorbance ratio at $450 \mathrm{~nm}$.

\section{Construction of plasmids}

Human $h T E R T$ promoter was isolated from volunteer blood using a DNA extraction kit (QIAGEN) according to the manufacturer's protocol. The $-211 /+40(\mathrm{pAP}-211 /+40)$ hTERT promoter regions was generated using the following two primers: pAP-211/+40: sense, 5'-GGTTTTAATTCCTGGTGTTTTCCGATC-3', and antisense, 5'-GCTCGCCTTCCTCCGCCTCCTTTGG-3'. The amplified product was digested with MluI and BglII restriction enzymes and ligated into pGL3-basic luciferase vector (Promega, Madison, WI) digested with the same enzymes. The AP-2a binding site was mutated using the Quick Change site mutagenesis kit (Stratagene). For the point mutation of AP-2a site on the pAP-211/ +40 mutant promoter region, the following primers were used: pAP-211/+40mut: sense, 5'-GCCTCTGCCAAGTCttCGGAGACGGAC-3', and antisense, 5' -CCTGTCCGAATGCTCCCGGAGCTCTCG-3' . The lowercase letters indicate mutation, and the underlined letters indicate the AP-2 binding site. Site-specific mutation 
was confirmed by DNA sequencing.

\section{Transfection of the luciferase reporter system}

A549 cells were plated in six-well plates at $2 \times 10^{5}$ cells/well in F-12K medium supplemented with $10 \%$ fetal bovine serum. After growth overnight, plasmid mixtures containing $2 \mu \mathrm{g}$ hTERT promoter linked to luciferase and $0.2 \mu \mathrm{g}$ of pRT-null (Promega) were transfected by GeneJemmer reagent according to the manufacturer's protocol. After $48 \mathrm{~h}$ of transfection, the cells were harvested in $1 \times$ luciferase lysis buffer, and luciferase activity was determined and normalized to the pRL-TK luciferase activity with a dual luciferase assay kit (Promega). For $n$-BP treatment, the cells were treated with the drug in the absence of serum for $24 \mathrm{~h}$ and then assayed for luciferase activity. The results were determined by three independent experiments.

\section{Antitumor activity in vivo}

Xenograft mice were used as a model system to study the cytotoxic effect of $n$-BP in vivo; implantation of cancer cells was performed similarly to previous reports. Male congenital athymic BALB/c nude $(n u / n u)$ mice were purchased from the National Sciences Council (Taipei, Taiwan), and all procedures were performed in compliance with the standard operating procedures of the Laboratory Animal Center of ILAN University (I-Lan, Taiwan). All experiments were carried out using 6- to 8-week-old mice weighing 18 to $22 \mathrm{~g}$. The mice were implanted with $5 \times 10^{6}$ cells sc into their backs. When the tumors reached 80 to $120 \mathrm{~mm}^{3}$ in volume, animals were divided randomly into control and test groups consisting of three mice per group (day 0 ). Daily $s c$ administration of $n$-BP, dissolved in a vehicle of vitamin $\mathrm{K}_{1}$ (STANDARD), was performed from days 0 to 4 , far from the inoculated tumor sites $(>1.5 \mathrm{~cm})$. The control group was treated with vehicle only. The mice were weighed three times a week up to days 21 to 28 to monitor effects and at the same time the tumor volume was determined by measurement of the length (L) and width $(\mathrm{W})$ of the tumor. The tumor volume at day $n\left(\mathrm{TV}_{n}\right)$ was calculated as TV (cubic millimeters) $=\left(\mathrm{L} \times \mathrm{W}^{2}\right) / 2$. The relative tumor volume at day $n\left(\mathrm{RTV}_{n}\right)$ versus that at day 0 was expressed according to the following formula: $\mathrm{RTV}_{n}=\mathrm{TV}_{n} / \mathrm{TV}_{0}$. Tumor regression [T/C (percent)] in treated versus control mice was calculated using $\mathrm{T} / \mathrm{C}$ (percent $)=($ mean RTV of treated group)/(mean RTV of control group $) \times 100$. Xenograft tumors as well as other vital organs of treated and control mice were harvested and fixed in $10 \%$ formalin, embedded in paraffin, and cut in 4-mm sections for histologic study.

\section{Immunohistochemical staining}

All tumor tissues (sc A549 tumors with or without $n$-BP treatment) were fixed in $10 \%$ formalin at $4{ }^{\circ} \mathrm{C}$ for $16 \mathrm{~h}$ and then embedded in paraffin. Paraffin sections $(5 \mu \mathrm{m})$ were deparaffinized in xylene and rehydrated through a graded series of ethanol solutions. The sections were incubated with blocking solution (5\% non-fat milk powder in phosphate-buffered saline) for $60 \mathrm{~min}$ at room temperature, followed by a $4{ }^{\circ} \mathrm{C}$ overnight incubation with anti-telomerase-mouse (1/100 dilution; abcam) and anti-caspase-3-rabbit monoclonal antibody (1/100 dilution; Cell Signaling Technology, Beverly, MA, USA) in PBS. Subsequently, the immune complexes were visualized using the LSAB2 system (Dako North America Inc, Carpinteria, CA), respectively, and then, incubated for $15 \mathrm{~min}$ with $0.5 \mathrm{mg} / \mathrm{mL}$ diaminobenzidine and $0.03 \%(v / v) \mathrm{H}_{2} \mathrm{O}_{2}$ in PBS. Finally, sections were counterstained with hematoxylin, mounted, observed under a light microscope at magnifications of $\times 400$, and photographed.

\section{Statistical analysis}

The data are shown as mean with standard deviation. The statistical difference was analyzed using the Student's $t$ test for normally distributed values and by nonparametric MannWhitney $U$ test for values of non-normal distribution. Values of $P<0.05$ were considered significant.

\section{Results}

n-Butylidenephthalide inhibited cell growth and induced apoptosis in human lung adenocarcinoma A549 cells were treated with different concentrations of $n$-BP for 24, 48 and $72 \mathrm{~h}$ and cell viability was determined by MTT assay (Figure 1A). n-BP treated cells exhibited reduced cell viability in a time- and dose-dependent manner. At the highest concentration $(100 \mu \mathrm{g} / \mathrm{mL})$ used, cell viability was inhibited $78.6 \%$. A549 cells were treated with the $\mathrm{IC}_{50}$ of $n$-BP (which we determined as $62.5 \mu \mathrm{g} / \mathrm{mL}$ ) for $48 \mathrm{~h}$, Flow cytometry analysis showed that treatment with $50 \mu \mathrm{g} / \mathrm{mL}$ of $n$-BP induced apoptosis in a significant numbers of cells $(37.56 \%-45.32 \%$ based on triplicate experiments) whereas almost no apoptotic cells were observed in the untreated samples (Figure 1B). These results indicated that $n$-BP could reduce the viability of A549 cells in a dose-dependent manner, likely due to significant levels of cell death.

$n$-BP inhibits telomerase activity while hTERT decreases $n$-BPinduced toxicity

We showed (Figure 2A) that A549 cells treated with 25 and $50 \mu \mathrm{g} / \mathrm{mL}$ of $n$-BP for $48 \mathrm{~h}$ showed a significant inhibition of telomerase activity (about 50\% and 85\%, respectively). High telomerase activity has previously been implicated in prolonged cellular lifespan ${ }^{[11-13]}$. In order to look at the effect of hTERT on $n$-BP induced apoptosis, we stably transfected A549 cells with an expression vector containing the full-length hTERT coding region in the sense orientation and used G418 to select a pooled population of stably transfected cells. The stably transfected cells expressed hTERT protein to a 2.0 -fold higher level when compared to empty vector-transfected cells (Figure 2B). Using a colony formation assay, we demonstrated that over-expression of hTERT decreased $n$-BP toxicity. In the presence of $50 \mu \mathrm{g} / \mathrm{mL}$ of $n$-BP, hTERT overexpression resulted in a significant mRNA and activity increase (Figure $2 \mathrm{~B}$ and 2C). Furthermore, in the presence of $50 \mu \mathrm{g} / \mathrm{mL} n$-BP, hTERT overexpression resulted in an obviously increase $(\sim 22 \%)$ of the clonogenic capacity of A549 cells (Figure 2D). 
A

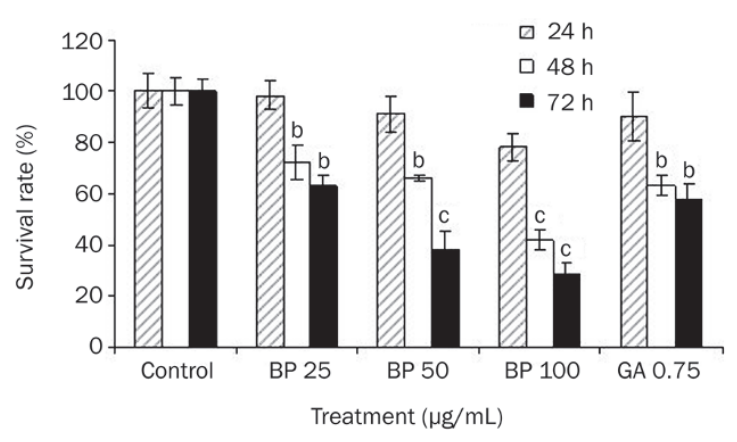

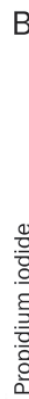

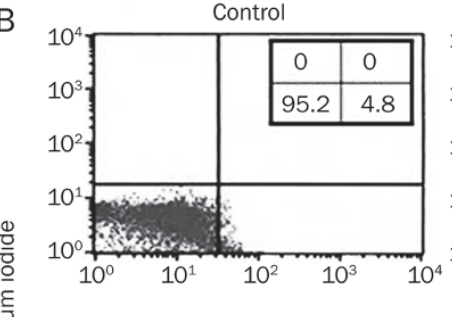

$50 \mu \mathrm{g} / \mathrm{mL}$ BP $24 \mathrm{~h}$

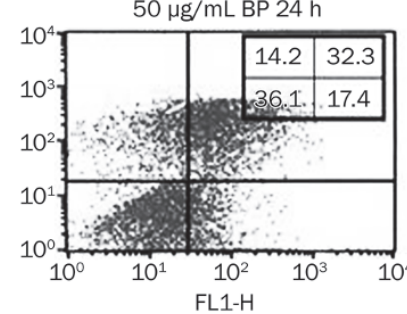

Annexin V-FITC

Figure 1. BP caused growth inhibition of human lung adenocarcinoma cells in vitro and induces apoptosis. (A) Growth inhibition effect was assessed in human lung cell lines A549. The cells were treated with various concentrations ranging from 25 to $100 \mu \mathrm{g} / \mathrm{mL}$ BP or vehicle (0.2\% DMSO) for various times $(24,48$, and $72 \mathrm{~h})$ as indicated. GAtreated cells were used as positive control. Growth inhibition effect $\left(\mathrm{IC}_{50}\right)$ was determined by MTT assay. (B) cells were treated with various concentrations of 0 to $50 \mu \mathrm{g} / \mathrm{mL}$ BP or vehicle for $24 \mathrm{~h}$. Cells were collected, and apoptosis was analyzed using $\mathrm{Pl} /$ Annexin $\mathrm{V}$ staining. The data represent the means \pm SD of three different experiments. ${ }^{b} P<0.05$, ${ }^{\mathrm{c}} P<0.01$ vs the control.

\section{Effect of $n$-BP on gene expression in A549 cells}

In order to investigate the effect of $n$-BP on hTERT expression, we treated hTERT overexpressing, A549 cells with various concentration of $n$-BP for various duration of time. Using reverse transcription-PCR and Western blot analysis, we demonstrated that hTERT mRNA and protein expression were significantly inhibited after 1 day of treatment. Additionally, hTERT and AP-2a were down-regulated by $n$-BP in a timeand dose-dependent manner in A549 cells (Figure 3) while the expression of $c-M y c$ and $S p 1$ genes showed no alteration.

The AP- $2 \alpha$ binding site has an important role in BP-inhibited hTERT expression

The region -211 to +40 of the hTERT promoter contains an $\mathrm{AP}-2 \mathrm{a}$ binding site, which plays a pivotal role in regulating basal gene expression ${ }^{[16]}$. We constructed a luciferase reporter using the -211 to +40 region of the hTERT promoter to drive the expression of the luciferase gene in order to evaluate the role of cis acting elements in n-BP-inhibited hTERT expression. These vehicle or constructs were transfected into A549 cells, which were then treated with $n$-BP for $24 \mathrm{~h}$. As an internal control, the plasmid pRL-null was used for adjusting transfection efficiency. $n$-BP treatment resulted in a 2.5 to 3.5 fold inhibition of luciferase activity in phTERT -211 to +40 transfected cells (Figure 4A) compared to negative control transfected cells where no increase in luciferase activity was seen. We performed a mutational analysis of the AP-2a site in the hTERT promoter in order to investigate the role of AP-2a in $n$-BP -induced hTERT expression. A site directed mutation of the AP-2a sites resulted in a dramatic reduction of luciferase activity $(\sim 80 \%)$ compared with the wild type construct (Figure $4 \mathrm{~B})$ suggesting that AP-2a may be involved in $n$-BP-inhibited hTERT expression.

\section{nBP-inhibited ERK activation followed by growth inhibition in A549 cells}

To determine whether MAPK/ERK, PKC, or PI3K/AKT/ GSK3 $\beta$ play a role in BP-induced growth inhibition of A549 cells, these cells were treated with BP in the presence or absence of the mitogen-activated protein kinase kinase $1 / 2$ inhibitor PD98059 (12.5-50 $\mu \mathrm{mol} / \mathrm{L})$, PI3K/AKT/GSK3 $\beta$ inhibitor LY294002 (5-20 $\mu \mathrm{mol} / \mathrm{L})$, or the PKC inhibitor GF1023X (5-20 $\mu \mathrm{mol} / \mathrm{L})$. It was shown that all the three inhibitors enhanced BP-induced growth inhibition in a concentration-dependent manner (Figure 5A). To determine which above mentioned pathways were involved in BPinduced growth inhibition, the effect of BP on ERK inhibition was assessed. Inhibition of phosphor-ERK protein expression was observed after exposure of A549 cells to BP. PKC protein expression had no obvious changes whereas phosphor-AKT protein expression was activated after drug treatment (Figure $5 \mathrm{~B})$. To investigate a possible role for ERK in the regulation of AP-2a, A549 cells were treated with BP in the presence or absence of the MAPK inhibitor PD98059. Using Western blot analysis, PD98059 had synergistic effects with $n$-BP in suppressing $\mathrm{AP}-2 \mathrm{a}$ and enhancing cleaved caspase- 3 protein levels (Figure 5C). These observations suggest that inhibition of the ERK1/2 signaling pathway was involved in $n$-BPinhibited AP-2a expression and led to apoptosis in A549 cells .

\section{$n$-BP blocks tumor growth in vivo by inhibition of hTERT}

In order to study the in vivo antitumor effect of $n$-BP on A549 cells (which may be partially mediated by hTERT expression), we established human lung cancer xenografts by sc injection of approximately $1 \times 10^{7}$ A549 cells on the backs of nude mice. After the tumor reached about $80-120 \mathrm{~mm}^{3}$ in size, the mice were randomized into vehicle control and treatment groups (six animals each) and given a daily sc injection of either 0 (control group), $100 \mathrm{mg} / \mathrm{kg}$ or $300 \mathrm{mg} / \mathrm{kg}$ of $n$-BP (treatment groups) for five consecutive days. The median tumor size was effectively decreased by up to $80 \%$ after treatment with 


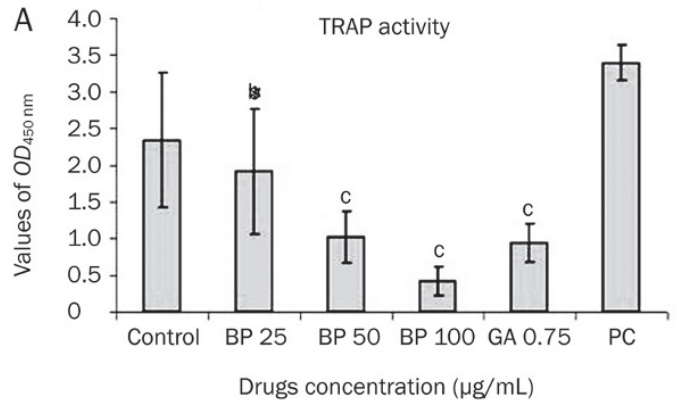

B

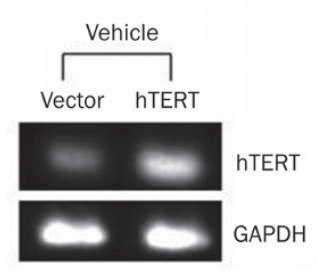

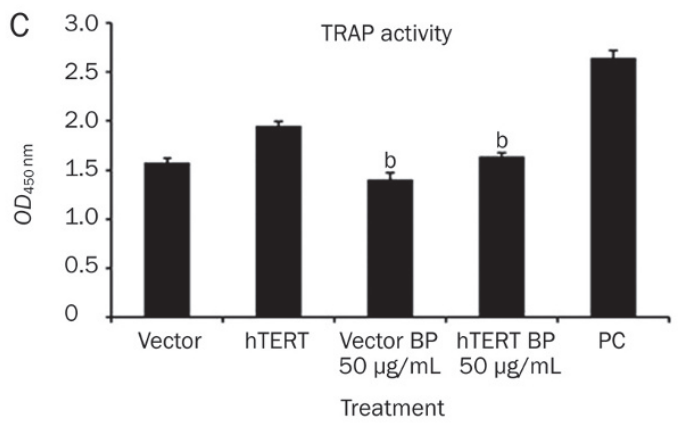

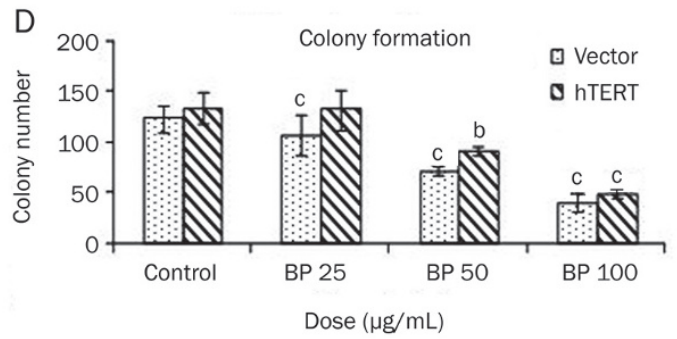

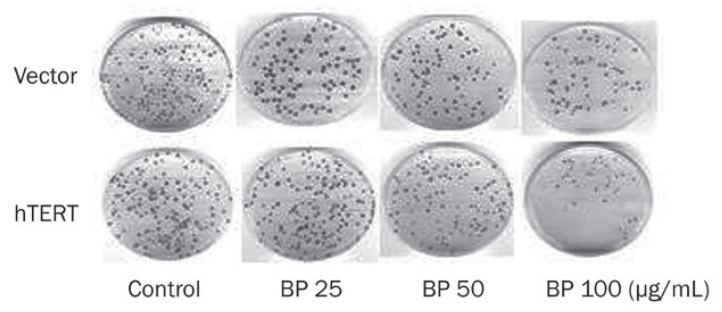

Figure 2. Effects of BP treatment on telomerase activity in human lung cancer cell line A549. (A) Telomerase was extracted from A549 cells treated with BP at various concentrations for a period of $48 \mathrm{~h}$. Telomerase activity was determined using the TRAP ELISA method as described in Materials and methods. Positive control (P.C.) represents assay with telomerase extract from kit, while DMSO is cells treated with solvent (0.1\% DMSO). GA indicated Gambogic acid-treated A549 cells. BP dose-dependently inhibited telomerase activity in the A549 cell line. The data represent the means \pm SD of three different experiments. ${ }^{b} P<0.05,{ }^{c} P<0.01$ vs the control. (B) The full-length hTERT was cloned into $\mathrm{pCl}$-neo5.4 expression vector and trnasfected into A549 cells. Each cell was grown under G418 (500 $\mathrm{kg} / \mathrm{mL})$ for 2 weeks. Total mRNA of $2 \mu \mathrm{g}$ was loaded in each lane and RT-PCR analysis was described in "Materials and Methods". (C) Telomerase activity in transfected A549 cells. A549 cells transfected with one of the pCl-neo5.4 (Cl-neo5.4; empty vector) and pCl-neo-hEST2-HA8.9 (hTERT) and incubated in the presence of BP (50 $\mathrm{gg} / \mathrm{mL})$ for $48 \mathrm{~h}$. Cells were collected and telomerase activity was analyzed using TRAP ELISA method. The data reveals that A549 cells contain more activity of hTERT than vector alone, and shown that BP could repress telomerase activity. The data represent the means \pm SD of three different experiments. ${ }^{b} P<0.05,{ }^{c} P<0.01$ vs the control. (D) Effects of hTERT expression on BP-induced apoptosis with colony formation. Colony formation assay using hTERT overexpression cells. A549 cells were transfected with either pCl-neo5.4 or pCl-neo-hEST2-HA8.9, and stably transfected clones were selected by exposoure to G418 (500 $\mu \mathrm{g} / \mathrm{mL})$ for $2 \mathrm{weeks}$. The stably transfected clones were treated with either vehicle or BP at various concentrations for a period of $48 \mathrm{~h}$ and then grown in culture medium for 2 weeks. The data represent the means \pm SD of three different experiments. ${ }^{b} P<0.05,{ }^{c} P<0.01$ vs the control.

A

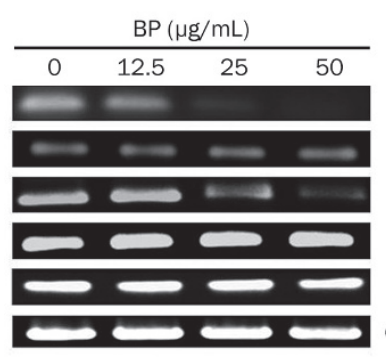

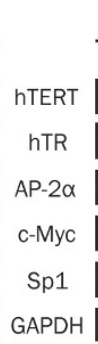

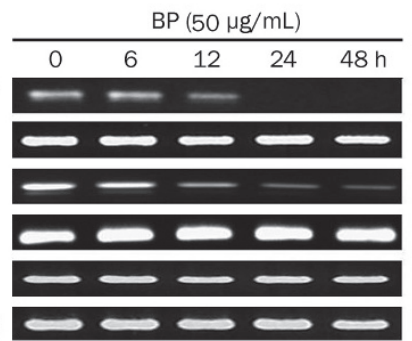

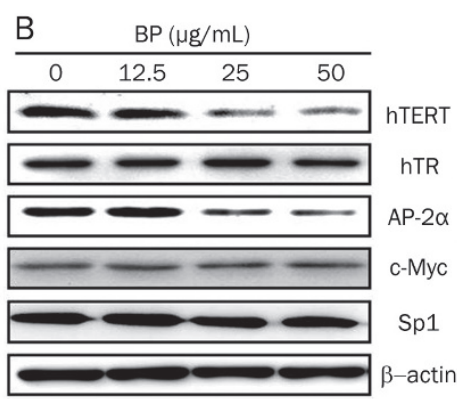

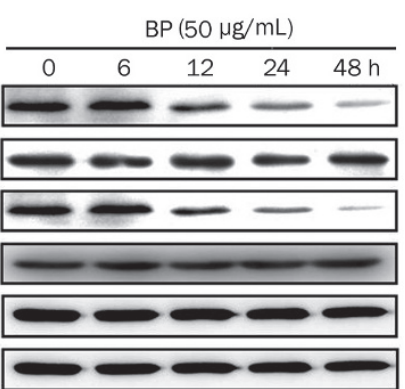

Figure 3. Effect of $n$-BP on mRNA and protein expression of hTERT, hTR, AP-2 $\alpha$, c-Myc and Sp1 in A549 cells. (A) mRNA expression of hTERT, hTR, AP$2 \alpha, c-M y c$ and Sp1 in the cells treated with various concentrations of $n-B P(0,12.5,25$ and $50 \mu \mathrm{g} / \mathrm{mL})$ for 2 days and the cells treated with $50 \mu \mathrm{g} / \mathrm{mL}$ $\mathrm{BP}$ or vehicle for various durations $(0,6,12,24$, and $48 \mathrm{~h})$ as indicated. Cells were collected and total RNA isolated for RT-PCR analysis, and expression of GAPDH was used as an internal control. (B) protein expressions of hTERT, hTR, AP-2 $\alpha, c-M y c$ and Sp1 in the cells treated with various concentrations of $n-\mathrm{BP}(0,12.5,25$ and $50 \mu \mathrm{g} / \mathrm{mL})$ for 2 days and the cells treated with $50 \mu \mathrm{g} / \mathrm{mL} \mathrm{BP}$ or vehicle for various durations $(0,6,12,24$, and $48 \mathrm{~h})$ as indicated. These expressions were assessed by Western blot assay, and expression of $\beta$-actin was used as an internal control.

n-BP (Figure 6A). In order to correlate the inhibition of tumor growth with hTERT expression, samples of the tumors were removed with a knife 35 days after the initiation of drug treatment. We showed by immunohistochemistry that there was a decrease in hTERT protein expression in tumor cells relative to the control group in vivo (Figure 6B). 
A

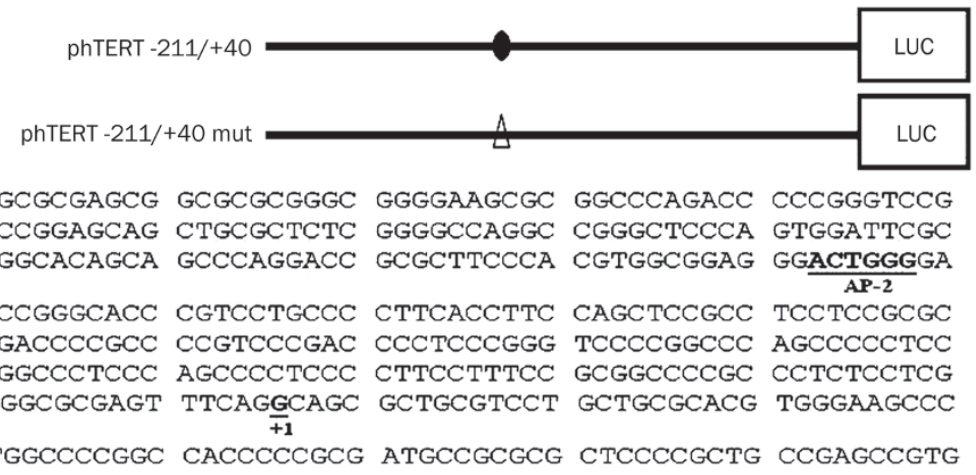

B

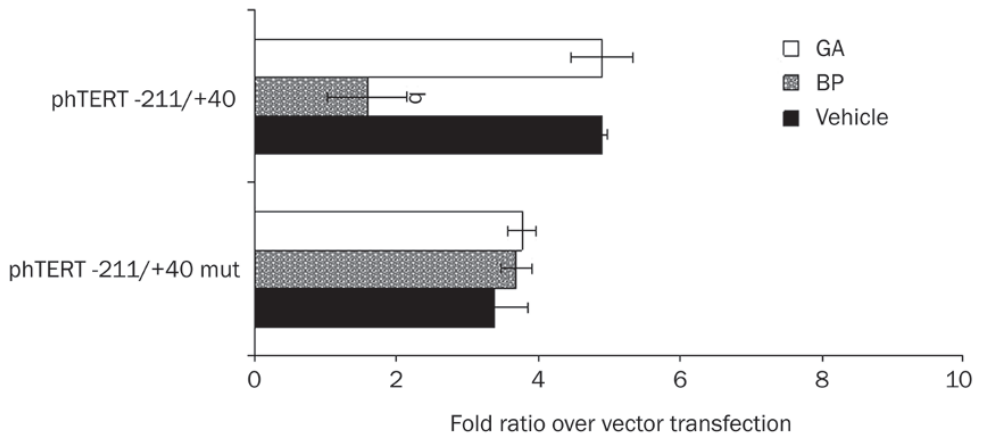

Figure 4. The AP- $2 \alpha$ binding site has an important role in BP-induced hTERT expression. (A) comparison of wild-type and mutant sequences between -211 and +40 in the hTERT promoter region. Mutated base pairs are indicated in each mutated sequence. (B) wildtype (phTERT $-211 /+40$ ) or AP-2 $\alpha$ mutant vector (phTERT -211/+40 mut) and pRL-null cotransfected into $\mathrm{A} 549$ cells. These indicated promoter regions were fused to a luciferase report gene. Each construct (2 $\mu g)$ was cotransfected with $0.2 \mu$ g of pRL-null vector into A549 cells using GeneJammmer transfection reagent followed by treatment with $50 \mu \mathrm{g} / \mathrm{mL}$ BP for $48 \mathrm{~h}$. Cells were lysed, and luciferase activity was measured. Transfection efficiency for luciferase activity was normalized to vehicle luciferase ( $p R L$-null vector). The $x$-axis shows relative luciferase units (RLU) (firefly luciferase/vehicle luciferase). The data represent the means $\pm S D$ of three different experiments. ${ }^{b} P<0.05$ vs the control.
A

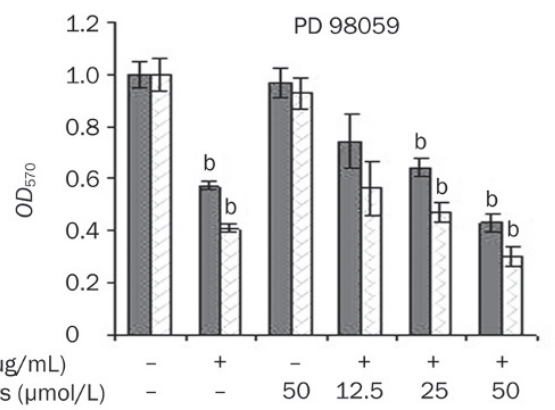

BP $(50 \mu \mathrm{g} / \mathrm{mL})$ Inhibitors ( $\mu \mathrm{mol} / \mathrm{L})$
B

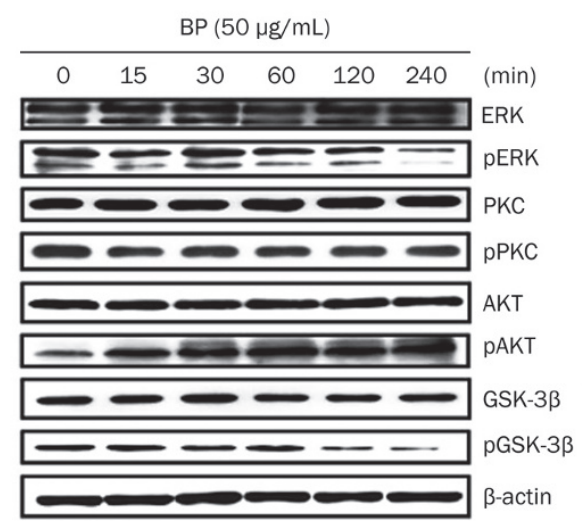

LY 294002
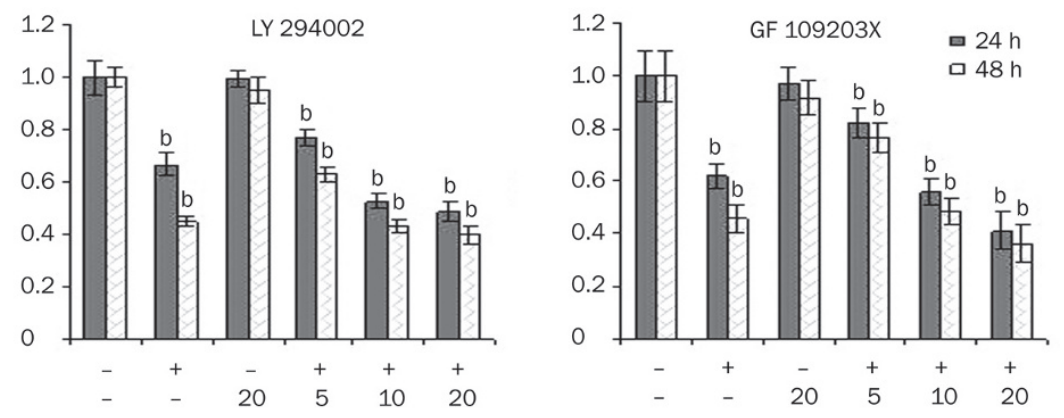

C

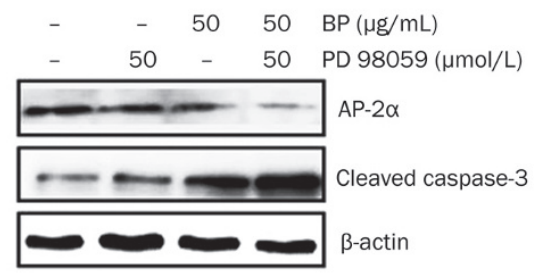

Figure 5. Inhibition of ERK expression and enhanced growth inhibition by MEK inhibitor PD98059. A, MTT assay of A549 cells with culture or serumcontaining medium pretreated with the MEK1/2 inhibitor PD98059 (12.5, 25, and $50 \mu \mathrm{mol} / \mathrm{L}$ ), the PKC inhibitor GF109203X (5, 10, and $20 \mu \mathrm{mol} / \mathrm{L})$, or the PI3K/AKT inhibitor LY294002 (5, 10, and $20 \mu \mathrm{mol} / \mathrm{L})$ for $1 \mathrm{~h}$ and then treated with $50 \mu \mathrm{g} / \mathrm{mL}$ BP for 24 and $48 \mathrm{~h}$. Lane 1 shows A549 cells treated with serum containing media and no test compound as a negative control. The data represent the means $\pm S D$ of three different experiments. ${ }^{b} P<0.05$, ${ }^{c} P<0.01$ vs the vehicle. B, Western blot analysis of ERK, phosphor-ERK (pERK), PKC, phosphor-PKC (pPKC), AKT, phosphor-AKT (pAKT), GSK-3 3 , and

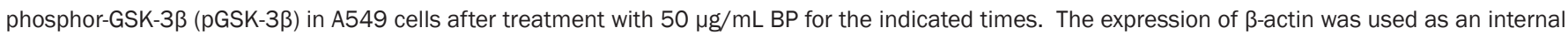
control. (C) Inhibition of AP-2 and enhancement of cleaved caspase-3 expression by MEK inhibitor in the BP-induced growth inhibition. A549 cells were in incubated in the presence or absence of the MEK inhibitor PD98059 for $1 \mathrm{~h}$ and then treated with BP for $12 \mathrm{~h}$. Western blot analysis was performed for AP- $2 \alpha$, cleaved caspase- 3 , and expression of $\beta$-actin was used as an internal control. 


\section{Discussion}

Reactivation of telomerase activity is a vital step in tumorigenesis. Beyond its role in telomere maintenance, telomerase provides additional functions in DNA repair and cell survival. Telomerase has been shown to protect cells from apoptosis and necrosis, and stimulate growth under adverse conditions ${ }^{[29]}$. Inhibition of telomerase activity in cancer cells is a potent factor in the abrogation of cellular immortalization. A number of different approaches have been developed to inhibit telomerase activity in human cancer cells. Different types of inhibitors targeting various regulatory levels have been regarded as useful for telomerase inhibition. Many telomerase inhibitors seem to be most efficient when combined with conventional chemotherapy. It has been demonstrated that telomerase may be involved in triggering apoptosis, but the underlying molecular mechanism remains unclear ${ }^{[30]}$. In the present study, we showed that $n$-BP treatment of A549 cells induced apoptosis and inhibited telomerase activity within $48 \mathrm{~h}$ of treatment. This was accompanied by a reduction of hTERT mRNA and hTERT protein. To explore the hypothesis that hTERT could determine BP cytotoxicity, A549 cells were stably transfected with a plasmid construct containing the coding region for human hTERT and we showed that A549 cells were protected from the cytotoxic effects of $n$-BP. We showed that BP inhibited the growth arrest and apoptosis in A549 cells through the up-regulation of the protein Telomerase, and our study suggests that telomerase is a critically important protein capable of reducing BP toxicity to A549 cells (Figure 2D).

These data together lead us to hypothesize that the tumorspecific activation of the hTERT promoter may be regulated by various cellular factors such as transcription factors and effectors, which are differentially activated in tumor cells or repressed in normal cells. The AP- $2 \alpha$ protein was selectively detected in DNA-binding protein complexes from lung cancer cells but not from normal cells. It was hypothesized that the AP- $2 \alpha$ isoform plays a key role in regulating hTERT gene expression in lung cancer development and progression. Our present study attempted to determine whether AP-2a inhibition in response to $n$-BP treatment was related to hTERT, A549 tumor cells were treated with $n$-BP or GA, a telomerase inhibitor (as a positive control) and shown by RT-PCR (Figure 3A) that $n$-BP inhibited AP-2 $\alpha$ and hTERT mRNA expression in a time dependent fashion. We explored the possible regulatory role of AP-2a on the hTERT promoter. Using our hTERT promoter, which contained AP-2a motif to drive the expression of a luciferase reporter, $n$-BP induced a two to three fold increase in luciferase activity compared to vehicle (Figure 4B). Mutation of the AP-2a binding sites did not increase $n$-BP mediated reporter gene expression (Figure $4 \mathrm{~B}$ ). Together, these result indicate that $n$-BP is associated with the AP-2a site of hTERT promoter.

It was shown that a phosphatidylinositol 3-kinase/AKT/ GSK3 (PI3K/AKT/GSK3 $\beta$ ) pathway regulates hTERT expression in human colorectal cancer cells as assessed by the inhibition of PI3K, AKT, and GSK3 $\beta$. PI3K inhibition by LY 294002 resulted in an increased hTERT protein and mRNA expression. 1L-6-hydroxymethyl-chiro-inositol 2(R)-2-O-methyl-3-Ooctadecylcarbonate (an AKT inhibitor) also previously induced NAG-1 expression ${ }^{[10,21-23]}$. In an attempt to identify the signaling pathway through which PI3K/AKT/GSK3 $\beta$ is involved in receptor signal transduction through tyrosine kinase receptors for n-BP, LY294002, a PI3K inhibitor, was examined. We found that LY294002 did not reverse tumor growth inhibition
A

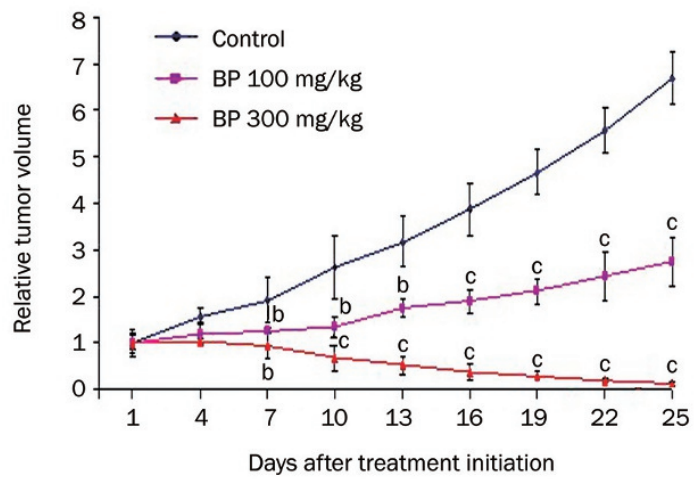

B

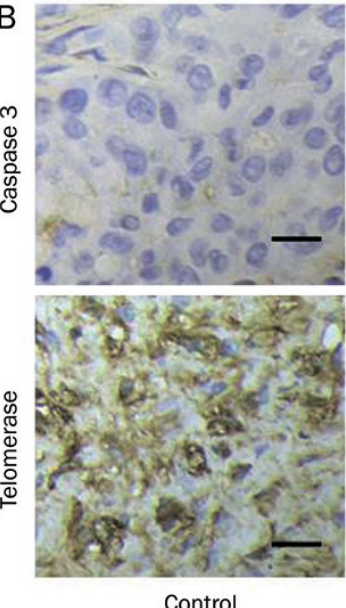

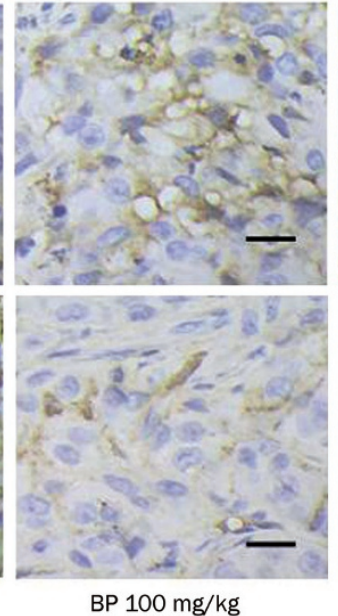

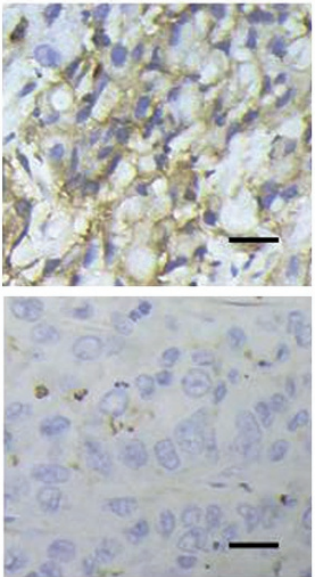

$\mathrm{BP} 300 \mathrm{mg} / \mathrm{kg}$

Figure 6. BP-induced in vivo growth inhibition of A549 xenografts in nude mice. Inhibition of tumor growth from A549 cells that downregulation of hTERT protein. Nude mice injected with approximately $5 \times 10^{6}$ A549 into the dorsal subcutaneous tissue. (A) When the tumor volumes reached $80-$

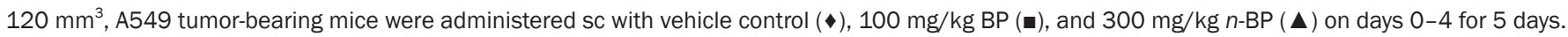
These figures shows A549 cells relative tumor volume of control and therapeutic groups. (B) immunohistochemical staining was analyzed in A549 tumor tissues (at day 10 after initiation of drug treatment). Representative photographs of sections of the control group and $n$-BP-treated group. A549 tumors, immunohistochemically stained with hTERT and caspase- 3 rabbit polyclonal antibody, and hTERT and caspase- 3 positive cells were stained brown (black arrowheads) ( $\times 400$ ). Scale bars, $100 \mu \mathrm{m}$. $n=3$ different experiments. Means \pm SD. ${ }^{b} P<0.05,{ }^{c} P<0.01$ vs the control. 
caused by $n$-BP (Figure 5A). In addition, LY294002 could not enhance $n$-BP-inhibited AP-2a expression. Compared with the effects of other phytochemical agents, this result suggests that apoptosis caused by $n$-BP might not follow this pathway. It has been reported that treatment of HSC-1 cells with all-trans RA (ATRA) significantly suppressed their telomerase activity and the suppression of telomerase activity correlated with the decreased expression of mRNA of human telomerase catalytic subunit (hTERT). Phosphorylation of extracellular signal-regulated kinases (ERK) 1/2 and of the serine/threonine kinase Akt was significantly suppressed after ATRA treatment. Suppression of ERK1/2 and Akt activation is presumed to be involved in the RA-induced suppression of hTERT ${ }^{[39,40]}$. In this study, we found that $n$-BP inhibited ERK phosphorylation and the BP had a synergistically cytotoxic effect with MEK inhibitor PD98059 (Figure 5C). These observations suggest that inhibition of the ERK1/2 signaling pathway was involved in $n$-BP-inhibited AP-2a expression and led to apoptosis in A549 cells. Furthermore, it has been demonstrated that the induction of Nur77 by BP is a mechanism in brain and liver cancer $^{[37,38]}$. However, the mRNA expression of Nur77 did not obviously change in a time- and dose-dependent manner since hTERT has inhibited dramatically after treatment with $n$-BP in A549 cells (data not shown). At present, we did not how the effect of Nur77 was related to hTERT inhibition.

In summary, our previous studies showing growth inhibition and antitumor activity in specific tumor cell lines in vitro and inhibition of a variety of xenografts including A549 lung cancer cell in vivo ${ }^{[1,3]}$ led us to study the mechanisms underlying the anti-tumor activity of $n$-BP. Our results suggest a gene target for $n$-BP, which may be useful for future clinical applications.

\section{Acknowledgements}

This work was supported by Grants 96-2320-B-303-001-MY3 and 96-2320-B-303-002-MY2 from National Science Council of the Republic of China and was partially supported by the National Science Council Grants, NSC96 2320-B-039-032-MY3 and NSC96 3111-B-039-003 to Yung-luen YU.

Chyou-wei WEI, Chai-ching LIN, and Yung-luen YU contributed equally as first authors, and Yi-lin Sophia CHEN and Horng-jyh HARN shared equal corresponding authorship.

\section{Author contribution}

Shinn-zong LIN, Yi-lin Sophia CHEN, and Horng-jyh HARN designed research; Chyou-wei WEI performed research and analyzed data; Chai-ching LIN, Yung-luen YU, and Chai-yi LIN performed research; Po-cheng LIN, Min-tze WU, Chengjueng CHEN, and Wen-liang CHANG contributed new analytical tools and reagents; Yi-lin Sophia CHEN wrote the paper.

\section{References}

1 Blackburn EH. Telomerases. Annu Rev Biochem 1992; 61: 113-29.

2 Greider CW, Blackburn EH. A telomeric sequence in the RNA of tetrahymena telomerase required for telomere repeat synthesis. Nature 1989; 337: 331-7.
3 Blackburn EH. Structure and function of telomeres. Nature 1991; 350: 569-73.

4 Feng J, Funk WD, Wang SS, Weinrich SL, Avilion AA, Chiu CP, et al. The RNA component of human telomerase. Science 1995; 269: 1236-41.

5 Nakamura TM, Morin GB, Chapman KB, Weinrich SL, Andrews WH, Lingner J, et al. Telomerase catalytic subunit homologs from fission yeast and human. Science 1997; 277: 955-9.

6 Weinrich SL, Pruzan R, Ma L, Ouellette M, Tesmer VM, Holt SE, et al. Reconstitution of human telomerase with the template RNA component hTR and the catalytic protein subunit hTRT. Nat Genet 1997; 17: 498-502.

7 Boldrini L, Faviana P, Gisfredi S, Zucconi Y, Di Quirico D, Donati V, et al. Evaluation of telomerase in the development and progression of colon cancer. Int J Mol Med 2002; 10: 589-92.

8 Janknecht R. On the road to immortality: Htert upregulation in cancer cells. FEBS Lett 2004; 564: 9-13.

9 Kanaya T, Kyo S, Takakura M, Ito H, Namiki M, Inoue M. Htert is a critical determinant of telomerase activity in renal-cell carcinoma. Int J Cancer 1998; 78: 539-43.

10 Kim NW, Piatyszek MA, Prowse KR, Harley CB, West MD, Ho PL, et al. Specific association of human telomerase activity with immortal cells and cancer. Science 1994; 266: 2011-5.

11 Nakano K, Watney E, McDougall JK. Telomerase activity and expression of telomerase RNA component and telomerase catalytic subunit gene in cervical cancer. Am J Pathol 1998; 153: 857-64.

12 Park TW, Riethdorf S, Riethdorf L, Loning T, Janicke F. Differential telomerase activity, expression of the telomerase catalytic sub-unit and telomerase-RNA in ovarian tumors. Int J Cancer 1999; 84: 42631.

13 Rhyu MS. Telomeres, telomerase, and immortality. J Natl Cancer Inst 1995; 87: 884-94.

14 Katakura Y, Yamamoto K, Miyake O, Yasuda T, Uehara N, Nakata E, et al. Bidirectional regulation of telomerase activity in a subline derived from human lung adenocarcinoma. Biochem Biophys Res Commun 1997; 237: 313-7.

15 Lee JC, Jong HS, Yoo CG, Han SK, Shim YS, Kim YW. Telomerase activity in lung cancer cell lines and tissues. Lung Cancer 1998; 21: 99-103.

16 Sarvesvaran J, Going JJ, Milroy R, Kaye SB, Keith WN. Is small cell lung cancer the perfect target for anti-telomerase treatment? Carcinogenesis 1999; 20: 1649-51.

17 Taga S, Osaki T, Ohgami A, Imoto H, Yasumoto K. Prognostic impact of telomerase activity in non-small cell lung cancers. Ann Surg 1999; 230: 715-20.

18 Albanell J, Lonardo F, Rusch V, Engelhardt M, Langenfeld J, Han W, et al. High telomerase activity in primary lung cancers: association with increased cell proliferation rates and advanced pathologic stage. J Natl Cancer Inst 1997; 89: 1609-15.

19 Bilsland AE, Stevenson K, Atkinson S, Kolch W, Keith WN. Transcriptional repression of telomerase RNA gene expression by c-jun- $\mathrm{NH}_{2-}$ kinase and sp1/sp3. Cancer Res 2006; 66: 1363-70.

20 Kirkpatrick KL, Ogunkolade W, Elkak AE, Bustin S, Jenkins P, Ghilchick $\mathrm{M}$, et al. Htert expression in human breast cancer and non-cancerous breast tissue: correlation with tumour stage and c-myc expression. Breast Cancer Res Treat 2003; 77: 277-84.

$21 \mathrm{Ma} \mathrm{H}$, Urquidi V, Wong J, Kleeman J, Goodison S. Telomerase reverse transcriptase promoter regulation during myogenic differentiation of human RD rhabdomyosarcoma cells. Mol Cancer Res 2003; 1 : 739-46.

22 Pellikainen J, Naukkarinen A, Ropponen K, Rummukainen J, Kataja V, 
Kellokoski J, et al. Expression of HER2 and its association with AP-2 in breast cancer. Eur J Cancer 2004; 40: 1485-95.

$23 \mathrm{Li} \mathrm{H}$, Goswami PC, Domann FE. Ap-2gamma induces p21 expression, arrests cell cycle, and inhibits the tumor growth of human carcinoma cells. Neoplasia 2006; 8: 568-77.

24 Baldi A, Santini D, Battista T, Dragonetti E, Ferranti G, Petitti T, et al. Expression of AP-2 transcription factor and of its downstream target genes c-kit, E-cadherin and p21 in human cutaneous melanoma. J Cell Biochem 2001; 83: 364-72.

25 Wajapeyee N, Britto R, Ravishankar HM, Somasundaram K. Apoptosis induction by activator protein 2alpha involves transcriptional repression of bcl-2. J Biol Chem 2006; 281: 16207-19.

26 Ruiz M, Pettaway C, Song R, Stoeltzing O, Ellis L, Bar-Eli M. Activator protein 2alpha inhibits tumorigenicity and represses vascular endothelial growth factor transcription in prostate cancer cells. Cancer Res 2004; 64: 631-8.

27 Jean D, Gershenwald JE, Huang S, Luca M, Hudson MJ, Tainsky MA, et al. Loss of AP-2 results in up-regulation of mcam/muc18 and an increase in tumor growth and metastasis of human melanoma cells. J Biol Chem 1998; 273: 16501-8.

28 Pellikainen J, Kataja V, Ropponen K, Kellokoski J, Pietilainen T, Bohm $\mathrm{J}$, et al. Reduced nuclear expression of transcription factor AP-2 associates with aggressive breast cancer. Clin Cancer Res 2002; 8: 3487-95.

29 Anttila MA, Kellokoski JK, Moisio KI, Mitchell PJ, Saarikoski S, Syrjanen $\mathrm{K}$, et al. Expression of transcription factor AP-2alpha predicts survival in epithelial ovarian cancer. Br J Cancer 2000; 82: 1974-83.

30 Douglas DB, Akiyama Y, Carraway H, Belinsky SA, Esteller M, Gabrielson $\mathrm{E}$, et al. Hypermethylation of a small cpguanine-rich region correlates with loss of activator protein-2alpha expression during progression of breast cancer. Cancer Res 2004; 64: 1611-20.

31 Gershenwald JE, Sumner W, Calderone T, Wang Z, Huang S, BarEli M. Dominant-negative transcription factor AP-2 augments sb-2 melanoma tumor growth in vivo. Oncogene 2001; 20: 3363-75.
32 Heimberger AB, McGary EC, Suki D, Ruiz M, Wang H, Fuller GN, et al. Loss of the AP-2alpha transcription factor is associated with the grade of human gliomas. Clin Cancer Res 2005; 11: 267-72.

33 Ropponen KM, Kellokoski JK, Pirinen RT, Moisio KI, Eskelinen MJ, Alhava EM, et al. Expression of transcription factor AP-2 in colorectal adenomas and adenocarcinomas; comparison of immunohistochemistry and in situ hybridisation. J Clin Pathol 2001; 54: 533-8.

34 Kao ST, Yeh CC, Hsieh CC, Yang MD, Lee MR, Liu HS, et al. The Chinese medicine bu-zhong-yi-qi-tang inhibited proliferation of hepatoma cell lines by inducing apoptosis via $G_{0} / G_{1}$ arrest. Life Sci 2001; 69: 1485-96.

35 Tsai NM, Lin SZ, Lee CC, Chen SP, Su HC, Chang WL, et al. The antitumor effects of angelica sinensis on malignant brain tumors in vitro and in vivo. Clin Cancer Res 2005; 11: 3475-84.

36 Tsai NM, Chen YL, Lee CC, Lin PC, Cheng YL, Chang WL, et al. The natural compound $n$-butylidenephthalide derived from angelica sinensis inhibits malignant brain tumor growth in vitro and in vivo. J Neurochem 2006; 99: 1251-62.

37 Lin PC, Chen YL, Chiu SC, Yu YL, Chen SP, Chien MH, et al. Orphan nuclear receptor, nurr-77 was a possible target gene of butylidenephthalide chemotherapy on glioblastoma multiform brain tumor. J Neurochem 2008; 106: 1017-26.

38 Chen YL, Jian MH, Lin CC, Kang JC, Chen SP, Lin PC, et al. The induction of orphan nuclear receptor nur77 expression by $n$-butylenephthalide as pharmaceuticals on hepatocellular carcinoma cell therapy. Mol Pharmacol 2008; 74: 1046-58.

39 Budiyanto A, Bito T, Kunisada M, Ashida M, Ichihashi M, Ueda $M$. Inhibition of the epidermal growth factor receptor suppresses telomerase activity in HSC-1 human cutaneous squamous cell carcinoma. J Invest Dermatol 2003; 121: 1088-94.

40 Kunisada M, Budiyanto A, Bito T, Nishigori C, Ueda M. Retinoic acid suppresses telomerase activity in HSC-1 human cutaneous squamous cell carcinoma. Br J Dnermatol 2005; 152: 435-43. 